\title{
Will cells as cinema sell?
}

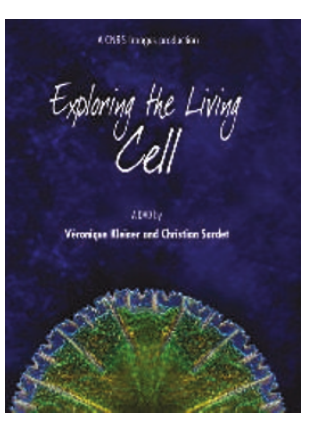

\section{Exploring the Living Cell}

A DVD by Véronique Kleiner and

Christian Sardet

CNRS Images • 2006

$35 €$ (private)/45€ (institution)

\section{Thoru Pederson}

This lively film produced by the developmental biologist Christian Sardet is laid out in five sections. The first is a historical account of the cell theory and light microscopy described by Paul Nurse, which dovetails with narrated images and other commentaries. Key pioneers in this area are accurately identified and this section has strong coherence. The second section, entitled "Evolution and Diversity", covers the origin of life, systematics and the endosymbiotic hypothesis. The lay narrator does a credible job here, but a parallel scientist commentator would have improved this section. The third section, "Voyage 3D", contains some of the best graphics of cell dynamics I have seen. Transcription and mitotic chromosome condensation are especially well done.

In the large section called "Research", the discussion on each topic has a leader and one or more other participants - usually post-docs or students in the primary commentator's group or institute. The segments in this section cover the cell's components and basic functions well. I thought the segments on centrosomes (led by Michel Bornens), the mitotic spindle (Eric Karsenti) and mitochondria (Michael Duchen) were especially good, with the cell-cycle segment by Nurse being the best. These viewpoints simply reflect my sense of the ideal audience for such as film (as discussed below) and all these sections are excellent in terms of the science presented.

The film closes with a section called "Debates" that has three segments. One is on stem cells, the second covers cells and evolution in the context of the intelligent design debate and the third, curiously titled "Cells and Program" (sic), attempts to explain information theory and systems biology. The basis for including this latter segment under "Debates" seems related to the old 'life as randomness versus order' conundrum.

The narrator's script might have been checked more carefully. She innocently recites some typographical errors and on some terms was clearly given no guidance on accurate pronunciation However, these occasional lapses do not mar the overall film. So, for whom is this film intended? The historical section will be richly educational for almost all practicing cell biologists. Conversely, the second section ("Evolution and Diversity") is far more elementary and seems aimed at laypersons or perhaps secondary

Thoru Pederson is in the Program in Cell Dynamics and the Department of Biochemistry and Molecular Pharmacology, University of Massachusetts Medical School, 377 Plantation St., Worcester, MA 01605, USA.

e-mail: thoru.pederson@umassmed.edu school students. The graphics section is terrific for everyone, including some children, but it is short and clearly not the major thrust of the film. The most substantial section ("Research") has an overall style that seems to reflect a desire to educate the general public, but this meets with mixed success. Several of the presenters do a good or excellent job of pitching to a lay audience, but this typically is not sustained when the camera swings to the laboratory and other personnel. A layperson would of course get a sense of the passion everyone has for their work, but there are so many expository lapses that the pedagogical aspect suffers. For example, in one scene a senior investigator shows a student how to run a deconvolution programme. He speaks in scientific peer terms while the student keeps responding as if talking to his parents. One of them just needs to say to the audience: "Even our best microscopes allow some stray light to blur

\section{The historical section will be richly educational for}

\section{almost all practicing cell biologists.}

the image, but we can use a computer to get rid of it and see just the actual biological structure we are investigating." In a segment on structural biology, lay viewers are given sufficient information to grasp that a purified protein population sometimes forms crystals and that the way an X-ray beam is broken up by the crystal can give information on the structure of the protein. But the very next instant the investigator says to his lab mate "Do you think we're dealing with hydrophobic interactions here?" With no attempt to define that term, a layperson viewer might wonder "Are they talking about rabies?"

In general, this film needed to be better scripted and the players more attentively coached so as to create a coherent style for a lay audience, or at the other extreme, a audience of their peers. In the latter case we would have little more than a collection of seminars, lab meetings, site visits etc., of questionable value (and unlikely the producer's intent). For the former, the contributions of Nurse are the defining style. However, I do recognize the enormous challenges inherent in making a film like this and think Kleiner and Sardet are to be commended on a very good start.

I will put this DVD to only a single use - one that may surprise some readers: donors (or donor prospects). In addressing lay audiences for eleemosynary purposes, I find that I am able to successfully describe much about biomedical science in general, and cell biology in particular, in words alone. But there comes a point when a layperson just has to see the real thing. One can troop a small donor group into the lab, but for larger audiences, some of the segments in this DVD will be terrific. These endeavours of institutional advancement, in which we teach laypersons about our glorious profession, are where this attractive DVD may have its greatest ultimate value.

Please refer to the following websites for more details about the DVD. http://www.bioclips.com/ $\mathrm{dvd} / \mathrm{http}: / /$ www.cns.fr/cnrs-images/videotheque/actualites/la-cellule/cellule-actu.01.htm 